\title{
Variability in the air-sea interaction patterns and timescales within the south-eastern Bay of Biscay, as observed by HF radar data
}

\author{
A. Fontán ${ }^{1}$, G. Esnaola ${ }^{1}$, J. Sáenz ${ }^{2}$, and M. González ${ }^{1}$ \\ ${ }^{1}$ AZTI-Tecnalia, Marine Research Division. Herrera Kaia, Portualdea z/g, 20110 Pasaia, Spain \\ ${ }^{2}$ Department of Applied Physics II, Fac. of Science and Technology and PIE-UPV/EHU, University of the Basque Country \\ UPV/EHU, Sarriena Auzoa z/g, 48940 Leioa, Spain \\ Correspondence to: A. Fontán (afontan@azti.es)
}

Received: 2 July 2012 - Published in Ocean Sci. Discuss.: 31 August 2012

Revised: 21 February 2013 - Accepted: 6 March 2013 - Published: 3 April 2013

\begin{abstract}
Two high-frequency (HF) radar stations were installed on the coast of the south-eastern Bay of Biscay in 2009, providing high spatial and temporal resolution and large spatial coverage of currents in the area for the first time. This has made it possible to quantitatively assess the air-sea interaction patterns and timescales for the period 2009-2010. The analysis was conducted using the Barnett-Preisendorfer approach to canonical correlation analysis (CCA) of reanalysis surface winds and HF radar-derived surface currents. The CCA yields two canonical patterns: the first windcurrent interaction pattern corresponds to the classical Ekman drift at the sea surface, whilst the second describes an anticyclonic/cyclonic surface circulation. The results obtained demonstrate that local winds play an important role in driving the upper water circulation. The wind-current interaction timescales are mainly related to diurnal breezes and synoptic variability. In particular, the breezes force diurnal currents in waters of the continental shelf and slope of the south-eastern Bay. It is concluded that the breezes may force diurnal currents over considerably wider areas than that covered by the HF radar, considering that the northern and southern continental shelves of the Bay exhibit stronger diurnal than annual wind amplitudes.
\end{abstract}

\section{Introduction}

The Bay of Biscay, located in the eastern North Atlantic Ocean, is characterised by its complex submarine topography. This consists of an abyssal plain with water depths of around $4500 \mathrm{~m}$. The continental slope, formed by the Ar- morican, Aquitaine and Cantabrian slopes, is the transition between the deep sea and the continental shelf. It is very steep and fractured by numerous canyons. The continental shelf (water depths of less than $200 \mathrm{~m}$ ) is wider in the northern part, whilst the southern part (Cantabrian shelf) is extremely narrow with a mean width between 30 and $40 \mathrm{~km}$. The study area, the south-eastern Bay of Biscay, is located in the innermost part of the Bay, where the orientation of the coast changes from east-west to north-south (Fig. 1). Here, the continental shelf is the narrowest ranging from just 7 to $20 \mathrm{~km}$ wide (Pascual et al., 2004; Lavín et al., 2006).

The atmospheric circulation over the Bay is characterised by prevailing winds from the west to south-west. However, the winds are not spatially homogeneous and vary seasonally. The wind tends to come from the south-west in winter and from the west and the north-west in summer (OSPAR, 2000). In particular, the dominant winds within the southeastern part of the Bay are from the south-west in winter and autumn, while they tend to be northwesterly and northeasterly in spring and summer.

The surface water circulation over the region is mainly forced by the wind and partially constrained by the bathymetry. As such, the surface flow over the abyssal plain is eastward in winter, whereas it is to the south and the southeast in summer in agreement with the seasonal wind-driven Ekman drift (Van Aken, 2002; Charria et al., 2012). Over the continental slope, the surface flow is derived from wind and thermohaline forcing. The slope current is markedly seasonal in relation to the seasonal wind regimen in the Bay. In winter the prevailing winds reinforce the slope current, flowing eastward along the Cantabrian slope. In summer this 
current appears to be westward or absent with the prevalence of the southward wind stress (Pingree and Le Cann, 1990; Van Aken, 2002). Over the continental shelf, on the other hand, the surface currents are the result of the combined effect of the wind, buoyancy and tides. In the southern part of the Bay (south of $45^{\circ} \mathrm{N}$ ), the tidal currents are relatively weak as the strength of the tidal currents is proportional to the shelf width (Koutsikopoulos and Le Cann, 1996). Lower volumes of river run-off and a much narrower shelf of the southern Bay make buoyant plumes much less persistent than those over the Armorican shelf. As a result the surface currents are predominantly wind induced in the south-eastern shelf of the Bay (Ibañez, 1979; González et al., 2004).

Overall, in the south-eastern Bay of Biscay, surface water circulation is primarily driven by the wind forcing at the coast (Fontán et al., 2009, 2013) and on the continental shelf (Ibáñez, 1979; Álvarez-Salgado et al., 2006; González et al., 2006). On the Cantabrian continental slope, the surface circulation appears to be related to thermohaline and wind forcing. Recently, Herbert et al. (2011) concluded that the slope surface currents are partially driven by wind forcing on daily timescales, as the local wind tends to favour or prevent the extension of the geostrophic current. It should be underlined, however, that most of the research undertaken on the surface circulation, in the south-eastern coastal and continental shelf areas (Ibáñez, 1979; González et al., 2004; Fontán et al., 2006; Fontán et al., 2009; and Fontán et al., 2013) together with that attempted in the south-eastern continental slope of the Bay (Caballero et al., 2008; González et al., 2008; Abascal et al., 2009; and Rubio et al., 2013), has been focused on short-term datasets and fixed locations (moored buoys) or model simulations. In particular, the surface current measurements are scattered in temporal and spatial distributions over the south-eastern Bay of Biscay. This lack of long-term and large spatial coverage measurements has impeded the understanding of the timescales and spatial patterns associated with the surface wind-induced currents over wider areas in the region, such as the one considered in this paper.

Recently, the Directorate of Emergency Attention and Meteorology (Basque Government) has established a regional system for operational oceanography in the area. Initially, the data acquisition system was formed by six coastal stations and two offshore buoys, which provide oceanographic and meteorological information at fixed locations. In 2009 the system was upgraded with the installation of a highfrequency (HF) radar array. This has greatly improved the data acquisition system, providing measurements of marine currents in the area with high temporal and spatial resolutions and large spatial coverage for the first time. To date, the only research published based on these HF radar current measurements is that of Rubio et al. (2011), which focused on the spatial and temporal distribution of inertial variability in the south-eastern Bay. The present study, made possible by these newly available observations, aimed to explore and quantitatively assess the air-sea interaction patterns and

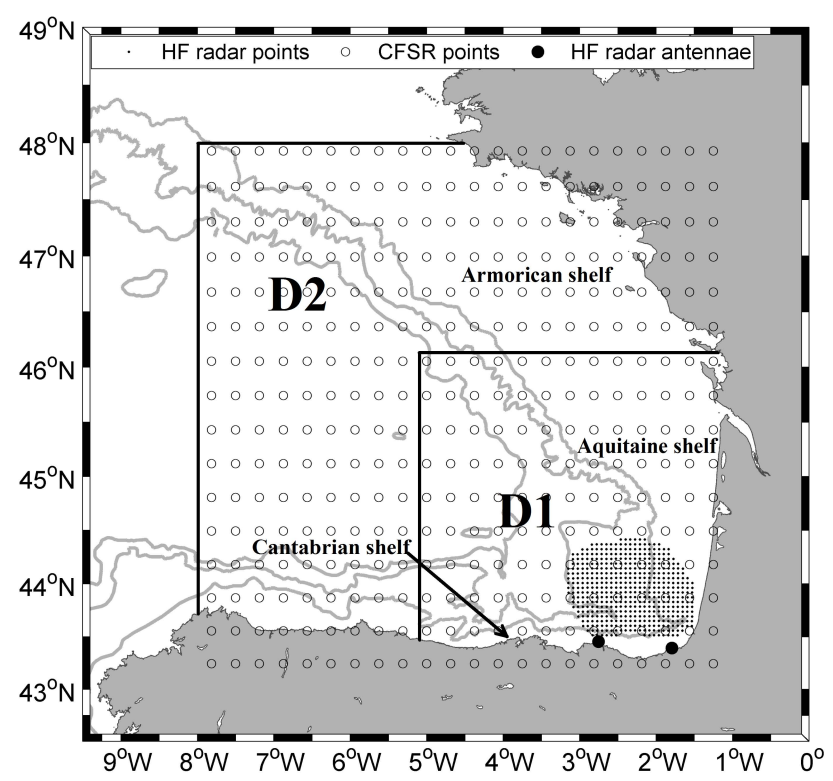

Fig. 1. Location of the study area showing the position of the HF radar points with more than $50 \%$ data coverage, CFSR grid points, HF radar antennae and the two spatial domains considered (D1 and D2). Bathymetric contours show the 200-, 2000- and 4000-m isobaths.

timescales within the south-eastern Bay of Biscay for the period 2009-2010. This has been accomplished by applying the Barnett and Preisendorfer (1987) approach to canonical correlation analysis (CCA) of surface wind and current fields with high spatial and temporal resolutions. The data and the analytical procedures adopted are described in Sect. 2. Section 3 presents the wind variability and its influence on surface water circulation. The wind-current interaction patterns and timescales are presented and discussed in Sect. 4. Finally, we summarise the new results and outline the main conclusions and future perspectives in Sect. 5 .

\section{Data and methods}

The data used in this study are hourly marine currents for a 2 year period (2009-2010) derived from the HF radar system. Two HF radar stations were installed on the coast of the south-eastern Bay of Biscay (see Fig. 1) and have been operational since 2009. The stations are equipped with CODAR SeaSonde systems, working in the $4.5 \mathrm{MHz}$ frequency band with a $40 \mathrm{kHz}$ bandwidth. The antennae cover a $150 \mathrm{~km}$ range with $5 \mathrm{~km}$ radial and $5^{\circ}$ angular resolutions. The data were preprocessed by applying standard procedures in accordance with the manufacturer's recommendations. Thus, radial velocities were obtained with the multiple signal classification (MUSIC) algorithm (Schmidt, 1986). These velocities were then moving-averaged over $3 \mathrm{~h}$ to increase the statistical robustness of the estimates. Hourly total current 

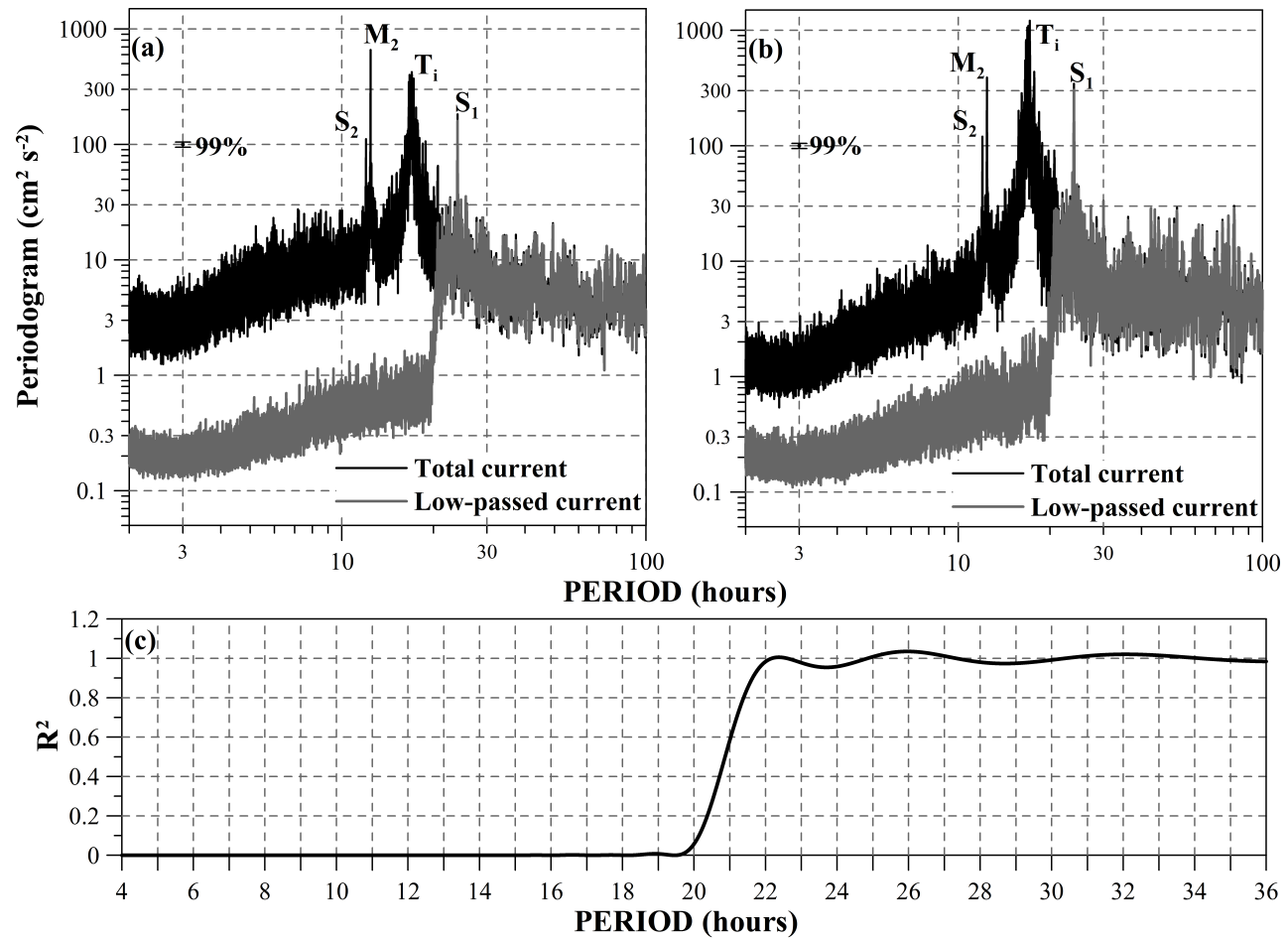

Fig. 2. Averaged Lomb-Scargle periodograms ( $99 \%$ confidence level) for (a) zonal and (b) meridional HF radar currents for the period 2009-2010. Spectra were computed on total and low-pass filtered currents. (c) Response factor $(R)$ of the low-pass filter (with a cut-off of $20 \mathrm{~h}$ and 137 points). Note: $S_{2}$ is semidiurnal principal solar gravitational tide, $M_{2}$ is semidiurnal principal lunar gravitational tide, $T_{i}$ is inertial period and $S_{1}$ is wind-induced (breezes) diurnal component.

vectors were obtained from these radial velocities by a leastsquares approach with an interpolation radius of $20 \mathrm{~km}$. Finally, hourly currents were derived over a regular mesh with a $5 \mathrm{~km}$ horizontal resolution. Standard quality control procedures were applied to radial and total velocities (Rubio et al., 2011). The HF radar currents were validated by Rubio et al. (2011); these authors concluded that the HF radar currents agree well with in situ measurements in the area.The wind components at $10 \mathrm{~m}$ a.s.l. of the Climate Forecast System Reanalysis (CFSR), provided by the National Centers for Environmental Prediction (NCEP), were also analysed in this study (Saha et al., 2010). The wind dataset covers the period 1979-2010 with spatial and temporal resolutions of $0.312^{\circ}$ and $1 \mathrm{~h}$, respectively. These data were used to describe the wind variability and the air-sea interaction patterns over the area. Xue et al. (2011) validated the surface winds from the CFSR and concluded that they generally agree well with the observations over the region.

The HF radar grid points with data coverage of more than $50 \%$ were selected for further analyses (Fig. 1). As the HF radar-derived currents contain data gaps, the Lomb-Scargle method was used to compute the periodogram of unevenly spaced data (Press et al., 1992). Spectra were determined for each HF radar grid point and were then averaged in order to increase the number of degrees of freedom of the spectral estimates. The high-frequency variability in surface currents is associated with semidiurnal $\left(M_{2}\right.$ and $\left.S_{2}\right)$, inertial $\left(T_{i}\right)$ and diurnal $\left(S_{1}\right)$ motions (see Fig. 2). In order to determine the wind-current interaction patterns and timescales, the effects of unwanted high-frequency motions, such as inertial and semidiurnal tidal variability, were eliminated by applying a low-pass filter specially designed to suppress those components (with a cut-off of $20 \mathrm{~h}$ and 137 points) (see Thompson (1983), for further details). This filter consists of a $137 \mathrm{~h}$ weighted moving average. Since the HF radar-derived currents are unequally spaced, this filter is applied provided that the filter weights $(w)$ satisfy $\left|1-\left(w_{0}+2 \sum_{k=1}^{N} w_{k}\right)\right|<0.4$ in each $137 \mathrm{~h}$ segment, where $k=1, \ldots, N$. This condition is easily accomplished if the neighbouring values are present, since the filter gives more weight to values at those points. Figure 2 shows that the semidiurnal tidal components $\left(S_{2}\right.$ and $\left.M_{2}\right)$ and the inertial motions $\left(T_{i}\right)$ have been efficiently eliminated from the currents by applying the digital filter. Conversely, as can also be seen in this figure, the wind-induced currents due to diurnal breezes $\left(S_{1}\right)$ have been preserved in the lowpass filtered currents. Low-pass filtering of the CFSR winds (with a cut-off period of $20 \mathrm{~h}$ ) was also performed to remove high-frequency signals. The low-pass filtered wind and current fields became the basis of subsequent analysis. 
CCA of the low-pass filtered surface current and wind fields, for the period 2009-2010, was used to characterise the wind-current interaction patterns and timescales across the south-eastern Bay of Biscay. This analysis identifies new basis vectors for two sets of variables such that the correlation between the projections of the variables onto these basis vectors are mutually maximised. In the present work, the Barnett and Preisendorfer (1987) approach to CCA was applied, which involves the application of empirical orthogonal function (EOF) analysis to the data prior to classical CCA. This approach presents advantages with respect to classical CCA: data compression, noise filtering and orthogonalisation. This statistical method is a common procedure in the atmospheric literature, but less widely used in the oceanic sciences (Sánchez et al., 2007). Some authors have applied the approach in a neighbouring oceanic area, namely the western Iberian Peninsula: Sánchez et al. (2007) studied the coupling between ocean winds and SST, while Herrera et al. (2008) applied the same approach to study the variability of thermohaline properties and residual currents and to quantify the local and remote processes driving these patterns (upwelling and river run-off, and meridional temperature gradient, respectively). To our knowledge, however, no studies to date have focused on wind-induced currents in the south-eastern Bay of Biscay.

Prior to calculating the EOF, all the data values were weighted by the square root of cosine of latitude to account for latitudinal distortion that occurs with a regular latitudelongitude grid (North et al., 1982). The presence of missing values in the HF radar time series was handled selecting only time steps with full spatial current data coverage, both for current and wind datasets. In total, the input time series to EOF analysis have $65 \%$ of missing values. However, the gaps have only an average duration of $51 \mathrm{~h}$, with $15 \mathrm{~h}$ being the most frequent length of missing values. Additionally, the distribution of the gaps across the seasons is sufficiently homogeneous as not to distort the results obtained in subsequent analyses. The EOF analysis was then applied for compressing the variability in both current and wind datasets. This was performed on both vector components by computing the eigenvalues and eigenvectors of their joint covariance matrix. The result is a compact description of the temporal and spatial variability of the datasets in terms of orthogonal functions, which are linear combinations of original variables. The new variables are called principal components (PCs) and are chosen to capture as much of the variability in the original datasets as possible (Wilks, 2006). Within the EOF analysis phase, the truncation criterion of the principal components was based on both North's rule of thumb (North et al., 1982) and a Monte Carlo test on the congruence coefficients between the EOFs obtained from 5000 random subsamples and those obtained from the whole sample (Cheng et al., 1995). It is worth noting that the time series presented here exhibit temporal autocorrelation and, consequently, it is to be expected that too many EOFs are retained by simple stopping rules (Navarra and Simoncini, 2010). As a first order approximation, the serial correlation was not considered in the EOF analysis, overestimating the number of EOFs retained. Afterwards, as part of the CCA phase, the optimum number of PCs to be retained for the CCA model was determined by a cross validation method (Feddersen, 2003; Feddersen and Andersen, 2005; Xoplaki et al., 2003; among others) that takes into account the temporal autocorrelation of the series. This enabled us to avoid overfitting in the CCA computations. The cross validation approach is a non-parametric resampling technique, where the available data are repeatedly divided into validation and verification subsets. For each time step, $t_{i}$, a CCA model is constructed based on data series that do not include values for a time interval, $\left(t_{i}-\tau, t_{i}+\tau\right)$, that considers there to be temporal autocorrelation over a time scale, $\tau$. Then this CCA model, formulated without making use of data in the $\left(t_{i}-\tau, t_{i}+\tau\right)$ interval, is tested on the skipped time $t_{i}$ observation. This process was repeated for each time step and for every combination of predictor-predictand truncations, yielding predictive skill scores. In particular, the performance of the CCA model was assessed using three indices: the correlation coefficient $(R)$, bias and root mean square error (RMSE). The criterion used to determine the optimal predictor-predictand truncation was to select the PCs that provided the best CCA model in terms of these indices. Subsequently, the statistical significance of the canonical correlation coefficients was additionally tested using a Monte Carlo technique. The time series were randomly resampled 5000 times, again taking into consideration serial correlation, to obtain a statistical distribution of the canonical correlations that happen by chance in those samples (Feddersen, 2003; Feddersen and Andersen, 2005). Finally, the sensitivity of the results to the spatial scales selected for the winds was also tested by repeating the analysis for two domains (D1 and D2 in Fig. 1). This allowed us to evaluate the influence of remote and local wind effects on surface currents.

\section{Atmospheric variability from reanalysis winds and its influence on surface circulation}

Over the study area the climatological winds vary spatially and on seasonal scales. The winds also vary on diurnal timescales, due to the so-called land and sea breezes. This is one of the most prominent mesoscale phenomena in coastal locations around the world (Kumar et al., 1986). The breezes are classified as mesoscale given their horizontal coverage and duration, with spatial scales of between 20 and $200 \mathrm{~km}$. Therefore, it is expected that the land and sea breezes may affect surface water circulation over these distances (20 to $200 \mathrm{~km}$ ) from the coastal areas.

To explore the influence of winds on surface circulation, the diurnal and annual amplitudes have been extracted from CFSR surface winds for the period 1979-2010 (Fig. 3). It 

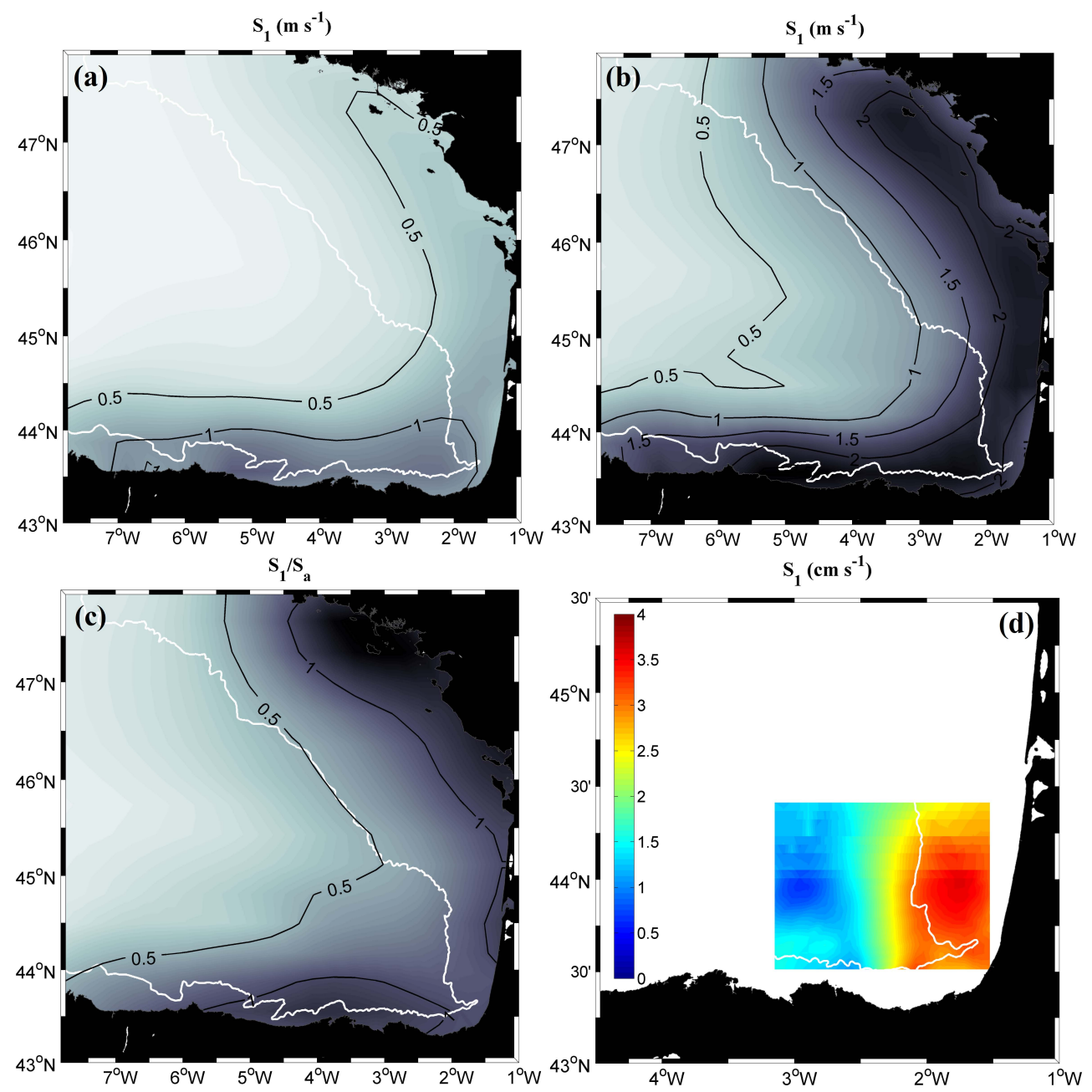

Fig. 3. The amplitude $\left(\mathrm{ms}^{-1}\right)$ of the diurnal $\left(S_{1}\right)$ harmonic of the surface wind speed from CFSR in the following: (a) wintertime (October to March) and (b) summertime (April to September) periods. (c) The ratio of the diurnal $\left(S_{1}\right)$ to the annual $\left(S_{\mathrm{a}}\right)$ components is also presented for the period 1979-2010. (d) The amplitude $\left(\mathrm{cm} \mathrm{s}^{-1}\right)$ of the diurnal harmonic of the surface current speed derived from HF radar for the period 2009-2010. Bathymetric contour (solid white line) shows the 200-m isobath.

can be seen that the breezes strengthen towards the coast, with larger amplitudes in the coastal and continental shelf areas (Fig. 3a and b). The diurnal component exceeds the annual component (the ratio is higher than 1) in some areas, the French continental shelf and the Cantabrian continental shelf and slope (Fig. 3c). The diurnal breezes also vary seasonally, being stronger in spring and summer (Fig. 3b) than in autumn and winter (Fig. 3a). Apart from the well-known influence of the breezes on the coastal circulation over the south-eastern Bay of Biscay (Fontán et al., 2009, 2013), they appear to affect the surface water circulation mainly on the continental shelf, and to a lesser extent the continental slope. Although the diurnal amplitudes extracted from HF radar observations correspond to the period 2009-2010 (Fig. 3d), the diurnal currents are stronger on the continental shelf and decrease offshore in a similar way to the distribution of diurnal breezes for the period 1979-2010 (Fig. 3a-c). This is also consistent with the results of the spectral analysis performed on the HF radar currents (Fig. 2): well-defined and significant peaks can be observed centred on the diurnal period for both zonal and meridional currents. These diurnal currents are not primarily forced by astronomical tides, but rather arise from diurnal breezes. In fact, diurnal tides and currents of astronomical origin are very weak in the Bay of Biscay (Le Cann, 1990).

The effect of breezes in coastal waters has been studied by Pielke (1981), who provided a comprehensive overview of the physical interactions between breezes and coastal waters. Several researchers (Hyder et al., 2002; Mihanović et al., 2009; Zaytsev et al., 2010; among others) have concluded that breezes induce surface-intensified diurnal variability in coastal water circulation. However, to our knowledge, research undertaken on the interaction of breezes with offshore waters is scarce. The results obtained in the present 
study provide new insights into the influence of land and sea breezes on diurnal motions in waters of the continental shelf and slope. In addition, the diurnal winds are stronger in the summertime and may generate stronger diurnal currents in the area. Finally, these findings indicate that land and sea breezes are probably affecting surface water circulation over wider areas (such as the Cantabrian and Armorican continental shelves) than that covered by the HF radar system (Fig. 3c).

\section{Air-sea interaction patterns and timescales}

Within this section, the wind-current interaction patterns and timescales are explored and quantitatively assessed by applying the CCA in the EOF space to wind and current datasets for the period 2009-2010. The Barnett and Preisendorfer (1987) approach to CCA was applied for the two different spatial domains (D1 and D2 in Fig. 1). Firstly, the number of predictors (i.e. winds) and predictands (i.e. currents) was prefiltered by applying the EOF analysis. This made it possible to compress the variability and to avoid internal correlations in both fields. As described in Sect. 2, the optimal number of retained modes was initially determined by North's rule of thumb (North et al., 1982) and a Monte Carlo test on the congruence coefficients (not shown). For the currents the 12 leading EOFs were non-degenerate (94\% of current variance). For the wind the truncation criterion was set to 14 for both D1 and D2 spatial domains, which accounted for 98$99 \%$ of the wind variability. Only the EOFs that passed the previous screening tests were considered in the next phase of the study. Subsequently, as mentioned in Sect. 2, the maximum number of EOFs to be retained in the CCA analysis was estimated by a cross validation approach (Feddersen, 2003; Feddersen and Andersen, 2005), taking into account the temporal autocorrelation of the series. To this end, the performance of the CCA model was tested by analysing all the combinations based on the 12 leading PCs for currents and the 14 leading PCs for winds for the two spatial domains (D1 and D2). The performance of the CCA model was evaluated by calculating the $R$ (Fig. 4a), bias (Fig. 4b) and RMSE (Fig. 4c) between the predicted and the withheld data. The abscissa axis in Fig. 4 represents the number of wind EOFs retained for the CCA model, whilst the ordinate axis corresponds to the number of EOFs used for currents. It can be seen that when increasing the number of wind EOFs above two, the correlation coefficient decreases and the RMSE increases, e.g. with six EOFs for the current data, and two EOFs for winds yields a value of $R=0.76$, whilst three wind EOFs reduces the value of $R$ to 0.65 . Consequently, increasing the number of current and wind EOFs above six and two, respectively, does not significantly improve the skill scores. Therefore, it can be concluded that the best predictive skills associated with the simplest model are obtained when the six and the two leading PCs of currents and winds, respectively,

\section{(a) $\mathbf{R}$}

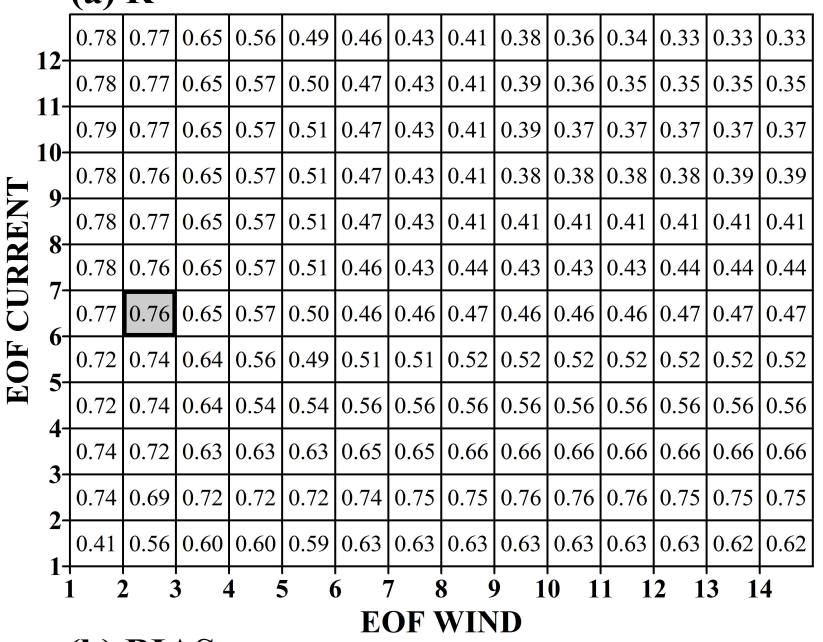

(b) BIAS

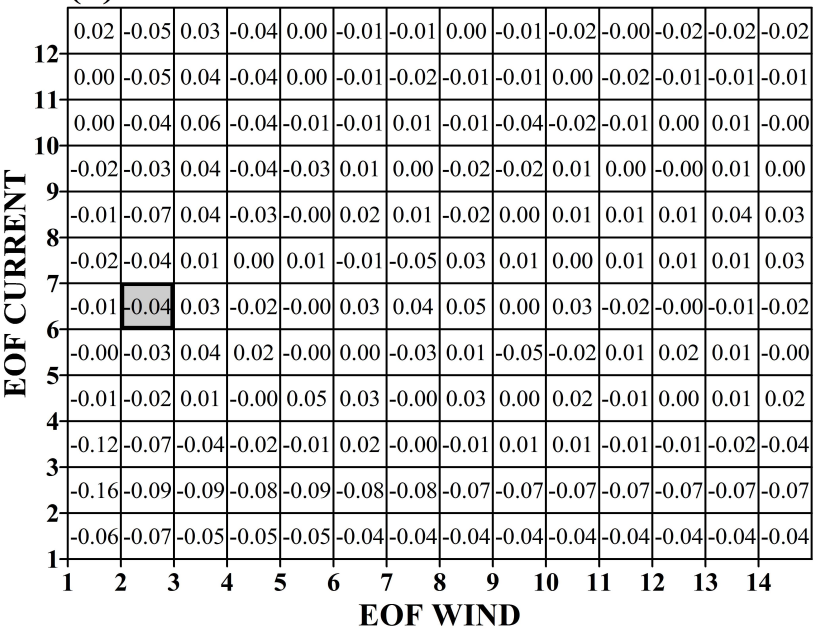

(c) RMSE

\begin{tabular}{|l|l|l|l|l|l|l|l|l|l|l|l|l|l|}
\hline 0.61 & 0.65 & 0.76 & 0.84 & 0.91 & 0.92 & 0.94 & 0.94 & 0.98 & 0.99 & 0.99 & 1.00 & 1.00 & 1.00 \\
\hline
\end{tabular}

\begin{tabular}{lllllllllllllllll}
12 & 0.61 & 0.65 & 0.76 & 0.83 & 0.89 & 0.91 & 0.93 & 0.94 & 0.97 & 0.99 & 0.99 & 0.99 & 0.99 & 0.99 \\
\hline
\end{tabular}

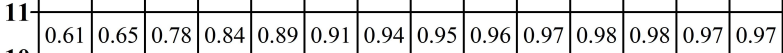

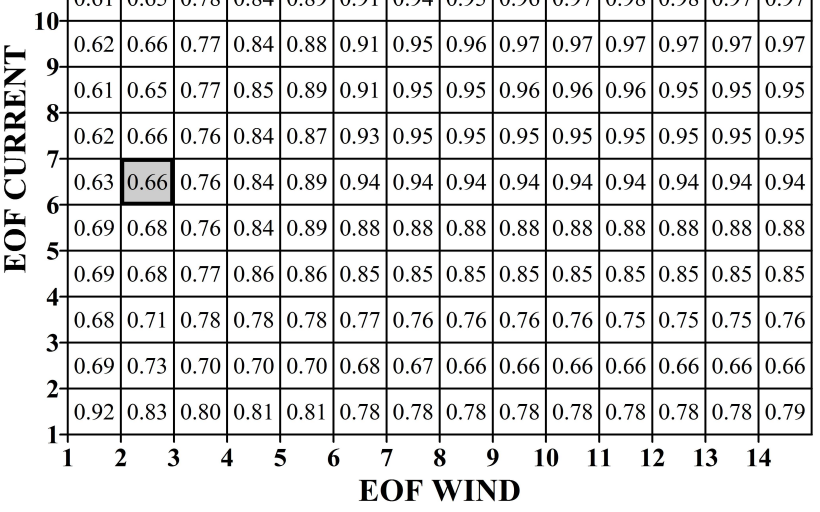

Fig. 4. Selection of the optimal CCA model for the D1 spatial domain by means of cross validation: (a) correlation coefficient $(R)$, (b) bias and (c) root mean square error (RMSE). 

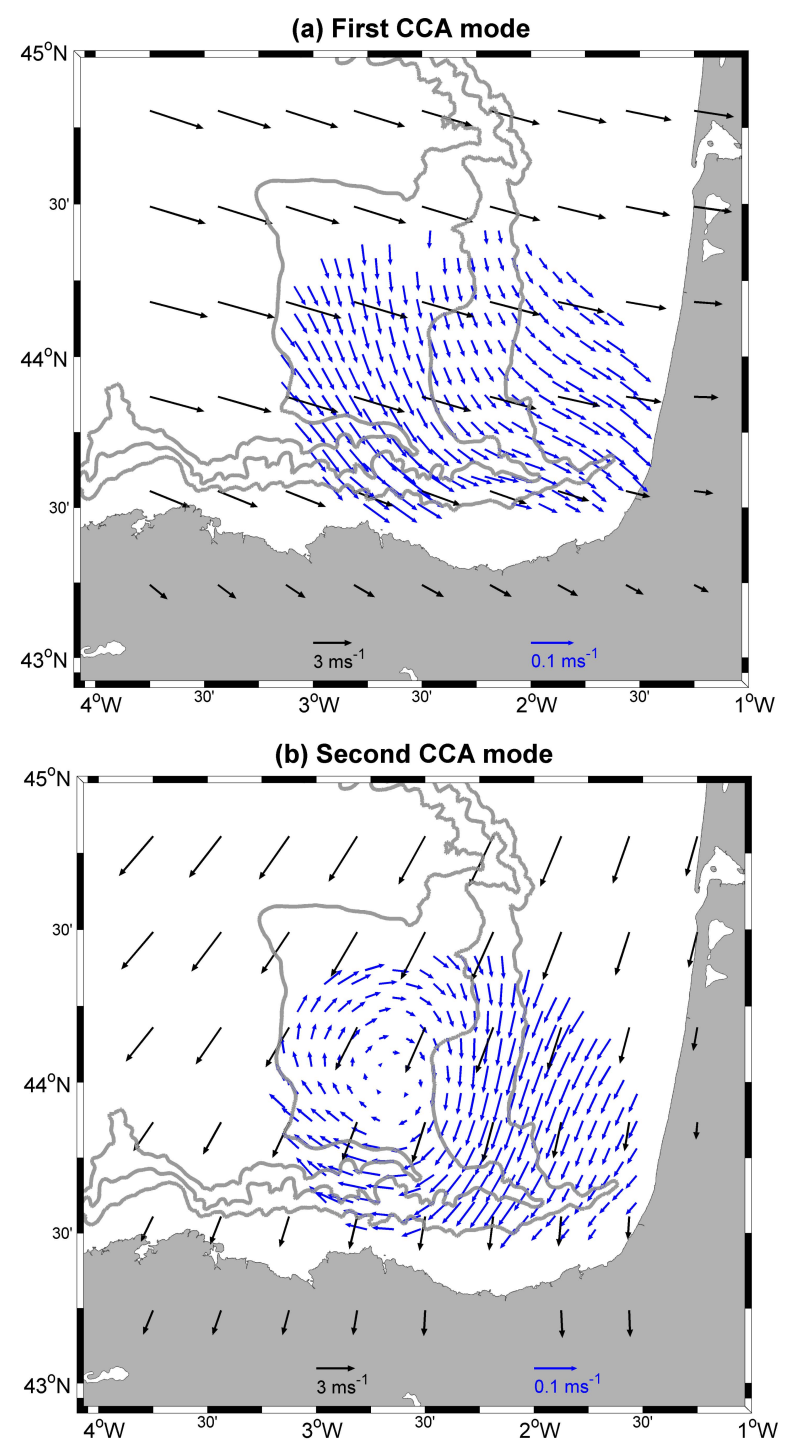

Fig. 5. Maps of homogeneous regression coefficients $\left(\mathrm{ms}^{-1}\right)$ (statistically significant at the $95 \%$ confidence level) of the (a) first and (b) second CCA modes for the currents (blue) and winds (black) for the D1 domain. Bathymetric contours show the 200-, 1000- and 2000-m isobaths.

are retained for the D1 domain. The results obtained are similar for the D2 domain (not shown).

Afterwards, CCA was performed on the two leading PCs of wind and the six leading PCs of currents $(87 \%$ and $86 \%$ of the current and wind variance, respectively) for the two spatial domains. The canonical correlation coefficients for mode 1 (2) for the D1 and D2 domains, respectively, are $0.84(0.70)$ and $0.79(0.57)$ (statistically significant above the $99.99 \%$ confidence level against the null hypothesis that the series are uncorrelated). The largest canonical correlation coefficients were obtained for the D1 domain. That is, the CCA model shows better results over shorter spatial scales (D1 do- main), which means that the currents over the study area are mainly forced by local rather than remote winds. Taking into consideration that the increase in the spatial domain does not improve the canonical correlations, only the D1 spatial domain will be considered herein. The winds and currents show the strongest correlation at zero lag, which indicates that the currents respond almost instantaneously to the wind forcing (note that the currents have been moving averaged over $3 \mathrm{~h}$ during data preprocessing).

The spatial patterns corresponding to each CCA mode have been scaled in the units of the original fields. To this end, maps of homogeneous regression coefficients have been constructed, i.e. the temporal expansion coefficients of canonical modes have been regressed onto the time series of both current and wind fields. Thus, the regression coefficients represent the change (in $\mathrm{m} \mathrm{s}^{-1}$ ) of the original fields associated with one unit change in the temporal expansion coefficients. The maps of the homogeneous regression coefficients between the original data and the temporal coefficients corresponding to each CCA mode are presented in Fig. 5. The first canonical mode shows a correlation, between the windand current-derived canonical variables, of 0.84 . Each canonical variable explains $43.7 \%$ of the wind and $25.8 \%$ of the current variance. Its corresponding spatial pattern shows that the currents flow at an angle with the driving wind (Fig. 5a). This is consistent with the wind-induced Ekman drift at sea surface. That is, the surface currents are found to be to the right of the wind forcing. The deflection angle between wind and current vectors shows a marked spatial and seasonal variability (Fig. 6). This angle increases from onshore (depth $<200 \mathrm{~m}$ ) to offshore (depth $>200 \mathrm{~m}$ ). It varies from 20 $35^{\circ}$ at the continental shelf to $60^{\circ}$ (at a maximum) offshore (Fig. 6a). In shallow water depths, the Ekman spiral motion is not fully developed and this leads to deflection angles which are less than the theoretical value of $45^{\circ}$. This is in agreement with the results of Kirincich et al. (2005) on the mid-shelf off central Oregon, Kim et al. (2009) in waters of San Diego and Ardhuin et al. (2009) on the western coast of France. In particular, Kim et al. (2009) have reported anisotropic and asymmetric coastal surface current response to the wind in relation to the bottom and coastline boundary effects. The deflection angle also varies seasonally, being larger in summer than in winter. Specifically, the deflection angles onshore change from $5-20^{\circ}$ in winter to $25-40^{\circ}$ in summer (Fig. $6 \mathrm{~b}$ and c). Offshore, the angles are around $55^{\circ}$ in winter and $70^{\circ}$ in summer at a maximum. Río and Hernández (2003) and Yoshikawa and Masuda (2009) also reported a larger deflection angle of the wind-induced flow in summer than in winter. This is explained by the increase in momentum penetration and the deepening of the Ekman layer in winter. Under these conditions the HF radar, with fixed measurement depth, measures a shallowest part of the Ekman layer, and therefore the deflection angle is smaller. Several authors have also reported Ekman wind-induced dynamics based on HF radar measurements. For instance, Son et al. (2007) also 

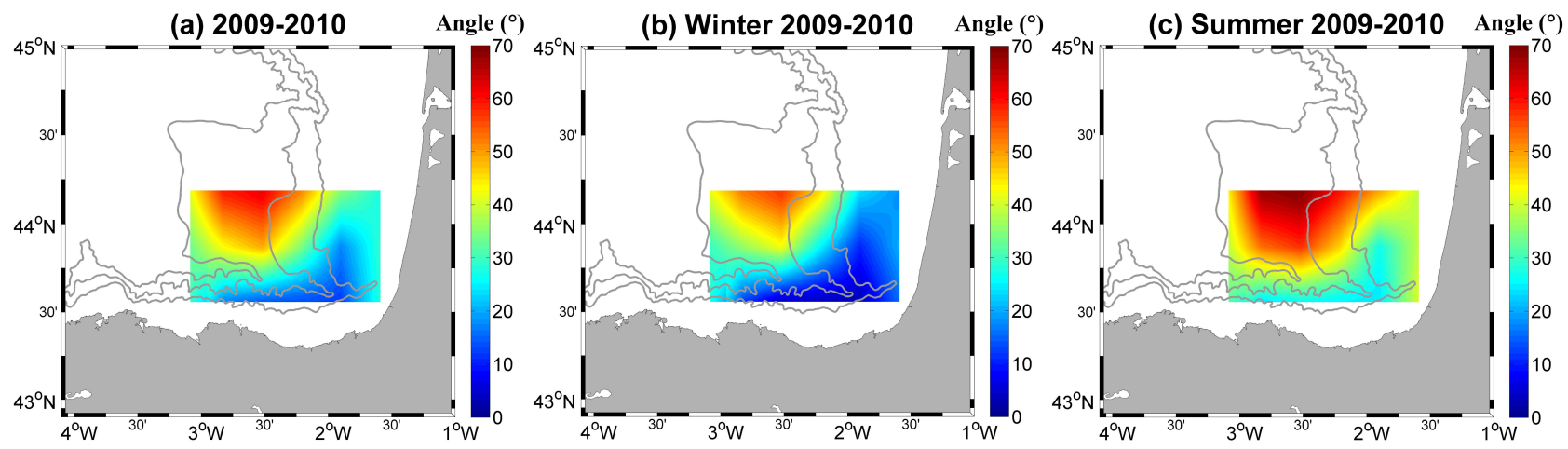

Fig. 6. Deflection angles of the wind-induced surface flows for the first CCA mode in: (a) 2009-2010, (b) wintertime (October to March) 2009-2010, and (c) summertime (April to September) 2009-2010 periods. Bathymetric contours show the 200-, 1000- and 2000-m isobaths.

described a response of the subtidal flow dominated by the Ekman effect in South Korea. Yoshikawa et al. (2007) identified a current profile corresponding to the Ekman spiral in the Tsushima Strait (based on observations from current profilers and HF radar) using EOF analysis. The wind impulse response and transfer functions have been widely discussed with HF radar currents in California and interpreted according to the Ekman theory by Kim et al. (2009, 2010). Zhao et al. (2011) also attributed the subtidal flow to Ekman windinduced dynamics in waters of Qingdao (China).

With regard to the second canonical mode, the canonical correlation is lower $(0.70)$ than that obtained for the first (0.84). However, the variance explained is similar to that of the first canonical mode: $42.3 \%$ of the wind and $26.0 \%$ of the current variability. This spatial pattern shows an anticyclonic surface water circulation for positive phases of the canonical expansion coefficients (anomalies are reversed for negative phases). This appears to be wind driven, excluding the north-westernmost area where the currents flow in the opposite direction to the wind forcing. In order to confirm that this second CCA mode is not an artefact, we repeated the analysis for two independent subsets of current data (not shown). The first subset corresponded to grid points in the continental shelf (depth $<200 \mathrm{~m}$ ), whilst the second subset grid points are distributed across the continental slope (depth $>200 \mathrm{~m}$ ). The results obtained indicate that both subsets yield the same canonical patterns, so that the second CCA mode is a robust feature and is not domain dependent.

Pingree and Le Cann (1989) applied a barotropic model, forced by steady winds from a set of varying directions, to study the wind-driven residual currents over the Bay of Biscay. These authors obtained a cyclonic water response induced by a steady southwesterly wind over the south-eastern Bay of Biscay (their Fig. 4; Pingree and Le Cann, 1989). The reverse phase of Fig. $5 b$ (associated with negative phases of the expansion coefficients corresponding to the second mode) can be compared with their Fig. 4 (Pingree and Le Cann, 1989). This result is fully consistent with the anticyclonic/cyclonic water response in Fig. $5 \mathrm{~b}$ and provides a physical support to our results obtained by statistical analysis of observational data. These authors (Pingree and LeCann, 1989) found that the response of the shelf waters to steady wind forcing is very rapid, taking around 4 days. The estimation of the average lifetime (Mudelsee, 2002) of our second canonical expansion coefficients yields 2.1 days, which is in agreement with the results of Pingree and Le Cann (1989). In addition, Solabarrieta et al. (2013) have found a clear seasonality of the HF radar-derived surface currents at the southeastern Bay of Biscay, with a cyclonic and anticyclonic surface circulation during winter and summer months, respectively. Once again this is consistent with the second CCA mode presented in Fig. 5b. The positive phase of the expansion coefficients (Fig. 5b) shows an anticyclonic surface circulation pattern under the influence of NE winds (more frequent in summer), whereas the negative phase describes a cyclonic surface circulation associated with the prevalence of SW winds in winter.

The normalised periodograms of the canonical variables have been calculated in order to determine the wind-current interaction timescales (Fig. 7a, b). Well-defined and significant peaks (99\% confidence level) can be observed centred on the diurnal $\left(S_{1}\right)$ period for both canonical series. This finding confirms that the diurnal breezes generate currents not only in coastal locations (Fontán et al., 2013), but also on the continental shelf and slope, visible in Fig. 3. Several additional, but less well resolved, simultaneous spectral peaks on both wind- and current-derived canonical variables can be seen at synoptic timescales. No other spectral peaks can be observed, mainly due to the limited number of observations (only 2 years with $35 \%$ data coverage). Further research is needed to explore wind-current interaction timescales based on long-term data series. Finally, the temporal evolution of the normalised expansion coefficients of the first and the second canonical modes for the winds and currents is shown in Fig. 7c, d. The time series are highly coherent for both the first and the second canonical modes, as the canonical correlation coefficients indicate. The first and the second expansion coefficients revealed sharp inversions from positive to 

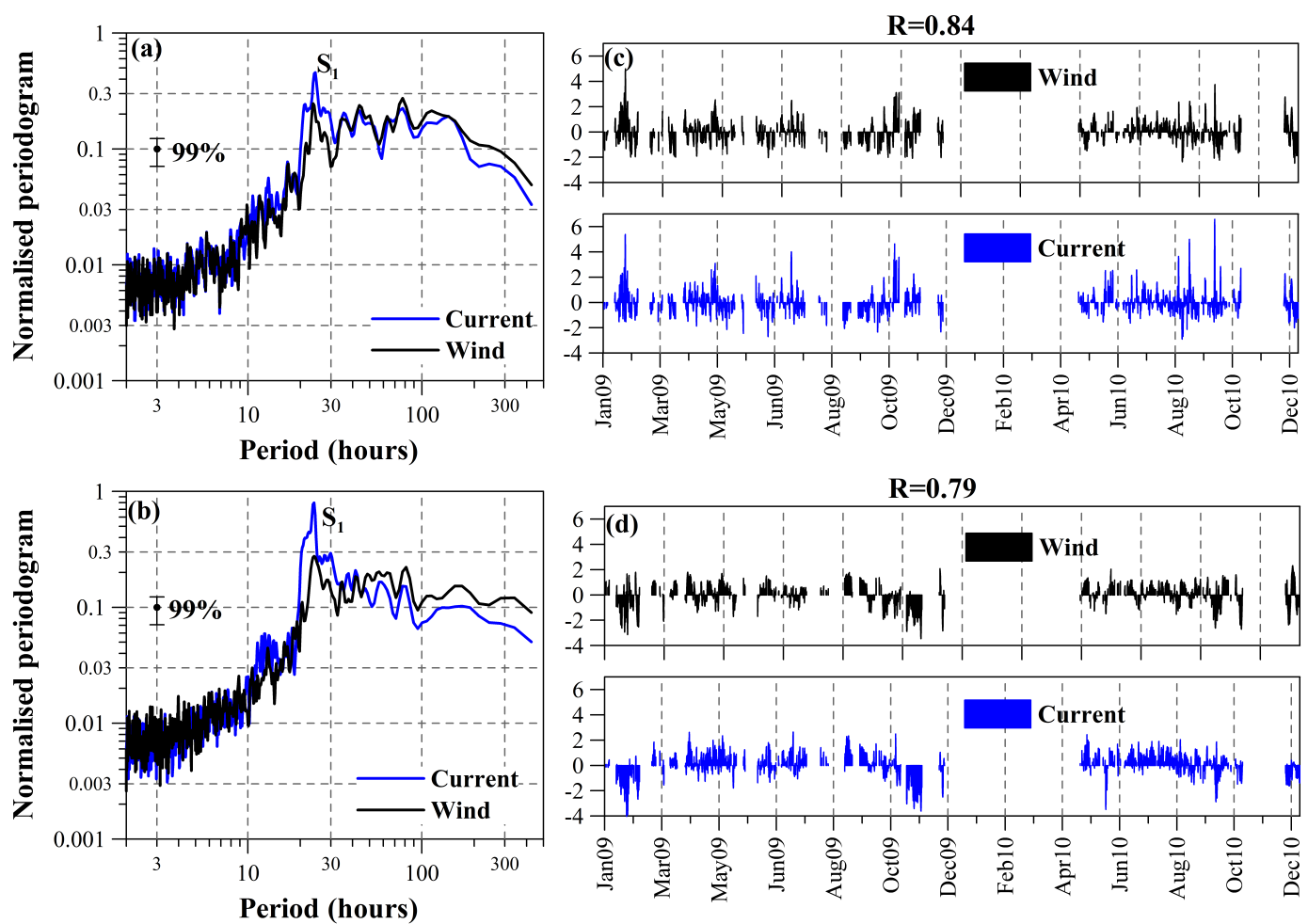

Fig. 7. Normalised Lomb-Scargle periodograms (99\% confidence level) for (a) the first and (b) the second canonical variables of currents (blue) and winds (black). Normalised time series of canonical expansion coefficients for (c) the first and (d) the second canonical modes of currents (blue) and winds (black). Note: $S_{1}$ indicates the diurnal wind component (breezes) and $R$ denotes the canonical correlation coefficient.

negative phases over daily timescales. This is consistent with the results of the spectral analysis, with the most energetic peaks being concentrated on diurnal and synoptic timescales.

\section{Concluding remarks and future perspectives}

The new results and the main conclusions obtained from the diagnostic of wind-induced currents in the south-eastern Bay of Biscay can be summarised as follows. In 2009, a HF radar monitoring system was installed on the coast of the southeastern Bay of Biscay. It provides coverage of surface currents over a large area with high spatial and temporal resolutions, giving an unprecedented picture of the upper circulation in the south-eastern corner of the Bay. The wind-current interaction spatial patterns and timescales in the area have, for the first time, been quantitatively assessed based on these measurements and reanalysis winds. However, it should be emphasised that this study covers only 2 years (2009-2010) with $35 \%$ data coverage. As a result, the conclusions derived are only applicable to this particular period of time. Time series of long duration should be considered in any further analysis.
The Barnett-Preisendorfer approach to CCA adequately addresses the purpose of this study. In particular, the air-sea interaction patterns obtained reveal that the local winds play an important role in driving the surface currents in the southeastern Bay of Biscay. The CCA yields two canonical patterns, modes 1 and 2, explaining $43.7 \%$ and $42.3 \%$ of the wind variance and $25.8 \%$ and $26.0 \%$ of the current variance, respectively. The first wind-current interaction pattern corresponds to the classical Ekman drift at the sea surface, with currents deflected clockwise with respect to the wind forcing. The deflection angle exhibits significant spatial and seasonal variability, being larger in summer and offshore. Conversely, the second canonical pattern reveals an anticyclonic/cyclonic water movement. This is agreement with the results of other authors, who described an anticyclonic surface circulation in summer and a cyclonic surface pattern in winter under the influence of the prevailing wind regimes. Further research is required to understand the driving mechanisms behind anticyclonic/cyclonic surface circulation.

With regard to the air-sea interaction timescales, these are related to diurnal periods, revealing that the breezes force diurnal currents at the continental shelf and slope. Synoptic wind circulation also affects surface water circulation over the area. The extension of the area, where the amplitude of diurnal cycle is larger than that of the seasonal cycle (Fig. 3), 
indicates that this process is probably affecting surface water circulation over considerably wider areas than that covered by the current HF radar system.

In recent years the literature reflects an increasing interest in statistical models based on HF radar currents. For instance, Zelenke (2005) developed a linear statistical model for short-term prediction of surface circulation based on wind forecasts and HF radar currents. O'Donnell et al. (2005) evaluated forecasting algorithms based on cross covariance functions between surface currents and winds. Recently, Frolov et al. (2012) proposed an empirical method for predicting surface currents based on the short history of HF radar observations and predicted winds by using EOF analysis. In the present case, the results obtained suggest that the EOF-CCA approach can also be suitable for developing a statistical prediction model related to surface winds and HF radar observations. The prediction of wind-induced surface currents can be undertaken based on accurate meteorological predictions at short timescales. This statistical model, for the prediction of wind-induced currents, would be combined with accurate predictions of tidal currents and inertial motions to derive the overall surface currents. In our opinion, the statistical model presented here is easier to implement and maintain than the classical numerical modelling. In addition, the performance and accuracy of the statistical modelling can be easily improved by increasing the number of observations. Finally, accurate and rapid predictions of surface currents will provide decision-makers with valuable information for oil spill detection, search and rescue, marine safety systems, offshore operations and risk assessment, among other applications. Future work of the authors will evaluate the feasibility of such a model.

Acknowledgements. The authors thank two anonymous reviewers and, particularly, the editor Mike Kosro for their very constructive comments, which have led to an improved version of the manuscript. The authors thank the Directorate of Emergency Attention and Meteorology of the Basque Government for establishing the operational data acquisition system. The authors acknowledge financial support from the ETORTEK Strategic Research Programme (Department of Industry, Trade and Tourism and Department of Transport and Civil Works of the Basque Government) through the ITSASEUS II project. The Basque Government (Department of Agriculture, Fisheries and Food) has funded the project "VARIACIONES". We thank Qualitas Remos for the work performed on HF radar data processing and also L. Solabarrieta for her enthusiasm and interest in the HF radar measurements. Jon Sáenz is grateful for financial support from projects CGL200803321 (Spanish National R+D+I Programme) and CTP10-03 PYNATEO (Basque Government). He also acknowledges funding provided by the University of the Basque Country (UFI 11/55, GIU 11/01 and PPM12/01). The wind data for this study are from the Research Data Archive (RDA), which is maintained by the Computational and Information Systems Laboratory (CISL) at the National Center for Atmospheric Research (NCAR). NCAR is sponsored by the National Science Foundation (NSF). The original data are available from the RDA (http://dss.ucar.edu) in dataset number ds093.1. G. Esnaola is supported by a research grant from the Fundación Centros Tecnológicos, Iñaki Goenaga. This is contribution number 618, of the Marine Research Division of AZTI-Tecnalia.

Edited by: M. Kosro

\section{References}

Abascal, A. J., Castanedo, S., Méndez, F. J., Medina, R., and Losada, I. J.: Calibration of a lagrangian transport model using drifting buoys deployed during the Prestige oil spill, J. Coast. Res., 25, 80-90, 2009.

Álvarez-Salgado, X. A., Herrera, J. L., Gago, J., Otero, P., Soriano, J. A., Pola, C. G., and García-Soto, C.: Influence of the oceanographic conditions during spring 2003 on the transport of the Prestige tanker fuel oil to the Galician coast, Mar. Pollut. Bull., 53, 239-249, 2006.

Ardhuin, F., Marié, L., Rascle, N., Forget, P., and Roland, A., Observation and estimation of Lagrangian, Stokes and Eulerian currents induced by wind and waves at the sea surface, J. Phys. Oceanogr., 39(11), 2820-2838, 2009.

Barnett, T. P. and Preisendorfer, R. W.: Origins and levels of monthly and seasonal forecast skill for United States surface air temperatures determined by canonical correlation analysis, Mon. Weather Rev., 115, 1825-1850, 1987.

Caballero, A., Espino, M., Sagarminaga, Y., Ferrer, L., Uriarte, A., and González, M.: Simulating the migration of drifters deployed in the Bay of Biscay, during the Prestige crisis, Mar. Pollut. Bull., 56, 475-482, 2008.

Charria, G., Lazure, P., Le Cann, B., Serpette, A., Reverdin, G., Louazel, S., Batifoulier, F., Dumas, F., Pichon, A., and Morel, Y.: Surface layer circulation derived from subsurface Lagrangian drifters in the Bay of Biscay, J. Mar. Syst., 109-110, S60-S76, 2013.

Cheng X., Nitsche, G., and Wallace, J. M.: Robustness of lowfrequency circulation patterns derived from EOF and rotated EOF analyses, J. Climate, 8, 1709-1713, 1995.

Feddersen, H.: Predictability of seasonal precipitation in the Nordic region, Tellus A, 55, 385-400, 2003.

Feddersen, H. and Andersen, U.: A method for statistical downscaling of seasonal ensemble predictions, Tellus A, 57, 398-408, 2005.

Fontán, A., Mader, J., González, M., Uriarte, Ad., Gyssels, P., and Collins, M.: Marine hydrodynamics between San Sebastián and Hondarribia (Guipúzcoa, Northern Spain): field measurements and numerical modelling, Sci. Mar., 70, 51-63, 2006.

Fontán, A., González, M., Wells, N., Collins, M., Mader, J., Ferrer, L., Esnaola, G., and Uriarte, A.: Tidal and wind-induced circulation within the southeastern limit of the Bay of Biscay: Pasaia Bay, Basque coast, Cont. Shelf Res., 29, 998-1007, 2009.

Fontán, A., Sáenz, J., González, M., Rubio, A., Esnaola, G., Liria, P., Ganzedo, U., Hernández, C., and Collins, M.: Coastal water circulation response to radiational and gravitational tides within the Southeastern Bay of Biscay, J. Mar. Syst., 109-110, S95S104, 2013. 
Frolov, S., Paduan, J., Cook, M., and Bellingham, J.: Improved statistical prediction of surface currents based on historic HF-radar observations, Ocean Dynam., 62, 1111-1122, 2012.

González, M., Uriarte, A., Fontán, A., Mader, J., and Gyssels, P.: Marine dynamics, in: Oceanography and Marine Environment of the Basque Country, edited by: Borja, Á., and Collins, M., Elsevier Oceanography Series No. 70, Elsevier, Amsterdam, 133157, 2004.

González, M., Uriarte, A., Pozo, R., and Collins, M.: The Prestige crisis: operational oceanography applied to oil recovery, by the Basque fishing fleet, Mar. Pollut. Bull., 53, 369-374, 2006.

González, M., Ferrer, L., Uriarte, A., and Urtizberea, A.: Operational oceanography system applied to the Prestige oil-spillage event, J. Mar. Syst., 72, 178-188, 2008.

Herbert, G., Ayoub, N., Marsaleix, P., and Lyard, F.: Signature of the coastal circulation variability in altimetric data in the Southern Bay of Biscay during winter and fall 2004, J. Mar. Syst., 88, 139158, 2011.

Herrera, J. L., Rosón, G., Varela, R., and Piedracoba, S.: Variability of the western Galician upwelling system (NW Spain) during an intensively sampled annual cycle. An EOF analysis approach, J. Mar. Syst., 72, 200-217, 2008.

Hyder, P., Simpson J. H., and Christopoulos S.: Sea-breeze forced diurnal surface currents in the Thermaikos Gulf, North-West Aegean, Cont. Shelf Res., 22, 585-601, 2002.

Ibáñez, M.: Hydrological studies and surface currents in the coastal area of the Bay of Biscay, Lurralde, 2, 37-75, 1979.

Kim, S. Y., Cornuelle, B. D., and Terrill, E. J.: Anisotropic response of surface currents to the wind in a coastal region, J. Phys. Oceanogr., 39, 1512-1533, doi:10.1175/2009JPO4013.1, 2009.

Kim, S. Y., Cornuelle, B. D., and Terrill, E. J.: Decomposing observations of high-frequency radar-derived surface currents by their forcing mechanisms: locally wind-driven surface currents, J. Geophys. Res., 115, C12046, doi:10.1029/2010JC006223, 2010.

Kirincich, A. R., Barth, J. A., Grantham, B. A., Menge, B. A., and Lubchenco, J.: Wind-driven inner-shelf circulation off central Oregon during summer, J. Geophys. Res., 110, doi:10.1029/2004JC002611, 2005.

Koutsikopoulos, C. and Le Cann, B.: Physical processes and hydrological structures related to the Bay of Biscay anchovy, Sci. Mar., 60, 9-19, 1996.

Kumar, A. R., Rao, M. P., and Murthy, J. S. R.: The effect of sea breeze on atmospheric stability as observed with acoustic sounder, Bound. Lay. Meteorol., 35, 303-311, 1986.

Lavín, A., Valdes, L., Sánchez, F., Abaunza, P., Forest, A., Boucher, J., Lazure, P., and Jegou, A. M.: The Bay of Biscay: the encountering of the ocean and the shelf, in: The Sea, Vol. 14B: The Global Coastal Ocean. Interdisciplinary Regional Studies and Syntheses, edited by: Robinson, A. R. and Brink, K., Harvard University Press, Cambridge, 933-1001, 2006.

Le Cann, B.: Barotropic tidal dynamics of the Bay of Biscay shelf: observations, numerical modelling and physical interpretation, Cont. Shelf Res., 10, 723-758, 1990.

Mihanović, H., Orlic, M., and Pasaric, Z.: Diurnal thermocline oscillations driven by tidal flow around an island in the Middle Adriatic, J. Mar. Syst., 78, 157-168, 2009.

Mudelsee, M.: TAUEST: A computer program for estimating persistence in unevenly spaced weather/climate time series, Comput. Geosci., 28, 69-72, 2002.
Navarra, A. and Simoncini, V.: A guide to Empirical Orthogonal Functions for Climate Data Analysis, Springer-Verlag, 151 pp., 2010.

North, G. R., Moeng, F. J., Bell, T. J., and Cahalan, R. F.: Sampling errors in the estimation of empirical orthogonal functions, Mon. Weather Rev., 110, 699-706, 1982.

O’Donnell, J., Ullman, D., Spaulding, M., Howlett, E., Fake, T., Hall, P., Tatsu, I., Edwards, C., Anderson, E., McClay, T., Kohut, J., Allen, A., Lester, S., and Lewandowski, M.: Integration of Coastal Ocean Dynamics Application Radar (CODAR) and Short-Term Prediction System (STPS) surface current estimates into the Search and Rescue Optimal Planning System (SAROPS), US Coast Guard Tech. Rep., USA, DTCG39-00-DR00008/HSCG32-04-J100052, 2005.

OSPAR: OSPAR Quality Status Report 2000, Region IV, Bay of Biscay and Iberian Coast, OSPAR Commission, London, 2000.

Pascual, A., Cearreta, A., Rodríguez-Lázaro, J., and Uriarte, A.: Geology and palaeoceanography, in: Oceanography and Marine Environment of the Basque Country, Elsevier Oceanography Series No. 70, edited by: Borja, Á. and Collins, M., Elsevier, Amsterdam, 53-73, 2004.

Pielke, R. A.: An overview of our current understanding of the physical interactions between the sea- and land-breeze and the coastal waters, Ocean Manage., 6, 87-100, 1981.

Pingree, R. D. and Le Cann, B.: Celtic and Armorican slope and shelf residual currents, Prog. Oceanog., 23, 303-338, 1989.

Pingree, R. D. and Le Cann, B.: Structure, strength and seasonality of the slope currents in the Bay of Biscay region, J. Mar. Biol. Assoc. UK, 70, 857-885, 1990.

Press, W. H., Flannery, B. P., Teukolsky, S. A., and Vetterling, W. T.: Numerical Recipes in Fortran 77: The Art of Scientific Computing, Cambridge University Press, Cambridge, 1992.

Río, M.-H. and Hernández, F.: High-frequency response of wind-driven currents measured by drifting buoys and altimetry over the world ocean, J. Geophys. Res., 108, 3283, doi:10.1029/2002JC001655, 2003.

Rubio, A., Reverdin, G., Fontán, A., González, M., and Mader, J.: Mapping near-inertial variability in the SE Bay of Biscay from HF radar data and two offshore moored buoys, Geophys. Res. Lett., 38, 1-6, 2011.

Rubio, A., Fontán, A., Lazure, P., González, M., Valencia, V., Ferrer, L., Mader, J., and Hernández, C.: Seasonal to tidal variability of currents and temperature in waters of the continental slope, Southeastern Bay of Biscay, J. Mar. Syst., 109-110, S121-S133, 2013.

Saha, S., Moorthi, S., Pan, H.-L., Wu, X., Wang, J., Nadiga, S., Tripp, P., Kistler, R., Woollen, J., Behringer, D., Liu, H., Stokes, D., Grumbine, R., Gayno, G., Wang, J., Hou, Y.-T., Chuang, H.Y., Juang, H.-M. H., Sela, J., Iredell, M., Treadon, R., Kleist, D., Van Delst, P., Keyser, D., Derber, J., Ek, M., Meng, J., Wei, H., Yang, R., Lord, S., Van Den Dool, H., Kumar, A., Wang, W., Long, C., Chelliah, M., Xue, Y., Huang, B., Schemm, J.-K., Ebisuzaki, W., Lin, R., Xie, P., Chen, M., Zhou, S., Higgins, W., Zou, C.-Z., Liu, Q., Chen, Y., Han, Y., Cucurull, L., Reynolds, R. W., Rutledge, G., and Goldberg, M.: The NCEP climate forecast system reanalysis, B. Am. Meteorol. Soc., 91, 1015-1057, 2010.

Sánchez, R. F., Relvas, P., and Delgado, M.: Coupled ocean wind and sea surface temperature patterns off the western Iberian Peninsula, J. Mar. Syst., 68, 103-127, 2007. 
Schmidt, R. O.: Multiple emitter location and signal parameter estimation, IEEE Trans. Antennas Propag., 34, 276-280, doi:10.1109/TAP.1986.1143830, 1986.

Solabarrieta, L., Rubio, A., Castanedo, A., Medina, R., Fernández, V., Charria, G., and Hernández, C.: Surface circulation patterns at the SE Bay of Biscay: New evidences from HF Radar data, in preparation, 2013.

Son, Y.-T., Lee, S.-H., Kim, C.-S., Lee, J. C., and Lee, G.-H.: Surface current variability in the Keum River Estuary (South Korea) during summer 2002 as observed by high-frequency radar and coastal monitoring buoy, Cont. Shelf Res., 27, 43-63, 2007.

Thompson, R. O. R. Y.: Low-pass filters to suppress inertial and tidal frequencies, J. Phys. Oceanogr., 13, 1077-1083, 1983.

Van Aken, H. M.: Surface currents in the Bay of Biscay as observed with drifters between 1995 and 1999, Deep-Sea Res. Pt. I, 49, 1071-1086, 2002.

Wilks, D. S.: Statistical Methods in the Atmospheric Sciences, 2 Edn., International Geophysics Series, Vol. 59, Academic Press, New York, 2006.

Xoplaki, E., González-Rouco, J. F, Luterbacher J., and Wanner, H.: Mediterranean summer air temperature variability and its connection to the large-scale atmospheric circulation and SSTs, Clim. Dynam., 20, 723-739, 2003.
Xue, Y., Huang, B., Hu, Z. Z., Kumar, A., Wen, C., Behringer, D., and Nadiga, S.: An assessment of oceanic variability in the NCEP climate forecast system reanalysis, Clim. Dynam., 37, 25112539, 2011.

Yoshikawa, Y., Matsuno, T., Marubayashi, K., and Fukudome, K.: A surface velocity spiral observed with ADCP and HF radar in the Tsushima strait, J. Geophys. Res., 112, C06022, doi:10.1029/2006JC003625, 2007.

Yoshikawa, Y. and Masuda, A.: Seasonal variations in the speed factor and deflection angle of the wind-driven surface flow in the Tsushima Strait, J. Geophys. Res., 114, C12022, doi:10.1029/2009JC005632, 2009.

Zaytsev, O., Rabinovich A. B., Thomson R. E., and Silverberg N.: Intense diurnal surface currents in the Bay of La Paz, Mexico, Cont. Shelf Res., 30, 608-619, 2010.

Zelenke, B. C.: An empirical statistical model relating winds and ocean surface currents: Implications for short-term current forecasts, M.S. thesis, Dept. of Oceanography, Oregon State University, Oregon, 94 pp., available at: http://hdl.handle.net/1957/ 2166, last access: 16 August 2012, 2005.

Zhao, J., Chen, X., Hu, W., Chen, J., and Guo, M.: Dynamics of surface currents over Qingdao coastal waters in August 2008, J. Geophys. Res., 116, C10020, doi:10.1029/2011JC006954, 2011. 